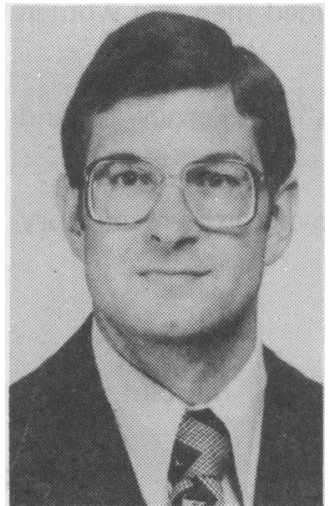

T. R. Thomas

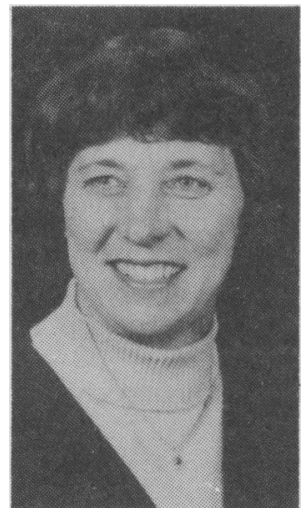

Carole Zebas

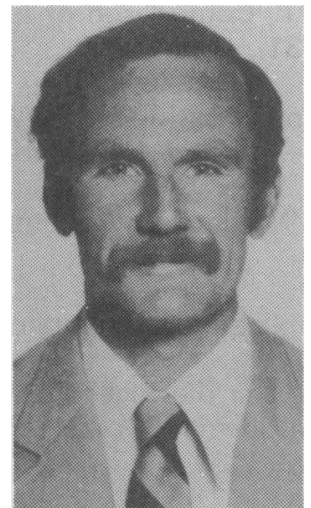

M. S. Bahrke

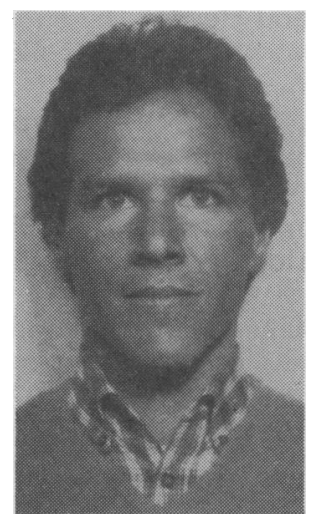

J. Araujo

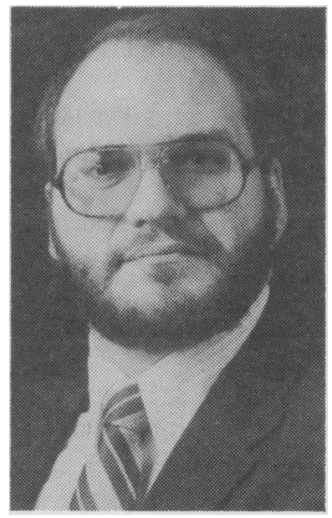

G. Etheridge

\title{
PHYSIOLOGICAL AND PSYCHOLOGICAL CORRELATES OF SUCCESS IN TRACK AND FIELD ATHLETES
}

\author{
T. R. THOMAS, PhD, Carole J. ZEBAS, PED, M. S. BAHRKE, PhD, J. ARAUJO, MA \\ and G. L. ETHERIDGE, PhD, AT, C
}

Department of Health, Physical Education \& Recreation, Robinson Center, University of Kansas, Lawrence, Kansas 66045

\section{ABSTRACT}

Twenty-four collegiate distance runners and 20 power athletes (sprinters and jumpers) of various success levels were tested on a number of physiological and psychological parameters. Multiple regression analysis indicated that physiological factors could explain over $\mathbf{8 1 \%}$ of the variance related to successful distance running while physiological and psychological factors could explain over $\mathbf{8 0 \%}$ of the variance related to successful sprinting and jumping. Body weight, fibre type, low density lipoprotein-cholesterol, and hamstring strength were significant singular correlates to successful distance running. Year in school, percent body fat, quadriceps strength, and leg muscle balance were significant single correlates to successful sprinting and jumping performance.

Key Words: Track and field, Muscular strength, Percent body fat, Blood lipids, Fibre type.

\section{INTRODUCTION}

The physiological characteristics of elite distance runners have been examined in a number of studies. However, the majority of previous research has focused on only a few of the numerous variables that may be important to performance. Maximal oxygen consumption (Costill et al, 1976b; Foster et al, 1978), enzyme activities (Costill et al, 1976a; Foster et al, 1978) and body composition (Pipes, 1977; Pollock et al, 1977) have been emphasised most. A composite profile of successful athletes in a given sport might be useful in predicting performance and even in selection of performers.

Previous work from our laboratories has identified the physiological characteristics of varsity track and field athletes in different events (Thomas et al, 1981). Distance runners had high $\mathrm{VO}_{2}$ max, while sprinters and jumpers had relatively low $\mathrm{VO}_{2}$ max and extremely low percent body fat. All track and field groups and control students had similiar plasma lipid profiles.

In addition to certain physiological characteristics, psychological indicators may also be important in distinguishing successful from unsuccessful athletes (Morgan, 1973). Other investigators have employed psychological testing to uncover variables pertinent to predicting and understanding athletic success in wrestling (Nagle et al, 1975; Morgan, 1968), rowing (Morgan, 1978; Williams, 1977), distance running (Morgan et al, 1977), and cycling (Hagberg et al, 1979). The utilisation of a composite physiological and psychological profile may better assess potential track and field success. 
In the present study, selected physiological and psychological factors were examined in order to determine their relationship to track and field performance. If specific physiological and psychological predictors of successful performers can be determined, then these characteristics might be used as goals in training programmes and for identifying events in which a given athlete has the greatest potential for success.

\section{METHODS}

Subjects were male volunteers, ages 17-22 years, from the University of Kansas varsity track and field team. The groups consisted of 24 distance runners, 10 sprinters, and 10 jumpers of various abilities $(N=44)$. Data were collected during the fall training period. All subjects had been training for several years, including the previous summer. After all procedures were explained, informed consent was obtained from each subject.

\section{Physiological testing}

All subjects were tested for maximal oxygen consumption, percent body fat, and plasma lipid profile as previously reported (Thomas and Etheridge, 1981). In brief, these tests included an exhaustive incremental treadmill run, assessment of body composition by hydrostatic weighing, and analysis of plasma for total cholesterol (Chol), total triglycerides (TG), high density lipoprotein cholestrol (HDL-C), and low density lipoprotein cholestrol (LDL-C). In addition, a muscle sample was obtained from the gastrocnemius by needle biopsy technique, and analysed for percent slow twitch fibre (Dubowitz, 1973).

Muscular strength was measured on a Cybex II Dynamometer with accompanying dual channel recorder. Quadriceps (knee extensor) and hamstrings (knee flexor) groups were assessed for strength with the subject in the seated position. A thigh stabilisation strap was secured around the leg being tested, and the knee joint axis was aligned with the lever arm axis of the dynamometer. Muscular strength was assessed at instrument velocity of $60 \% \mathrm{sec}$. Three complete flexionextension repetitions on each leg were performed, and the maximal value was used. Means and ratios were calculated from the raw scores (see Table I).

These physiological variables were selected from a variety of tests cited in the literature as being related to track and field performance. The tests used also represented those routinely performed in our laboratory.

\section{Psychological testing}

During a separate testing session subjects completed a battery of psychological inventories including the StateTrait Anxiety Inventory (STAI) (Spielberger et al, 1970) which measures transitory or state (SA) and constant or trait (TA) anxiety; the Eysenck Personality Inventory (EPI) (Eysenck et al, 1968) which measures extraversion-introversion and neuroticism-stability (this inventory also provides a psychometric lie score); and the Profile of Mood States (POMS) (McNair et al, 1971) which measures tension, depression, anger, vigour, fatigue and confusion. A composite psychological score, Total Mood Disturbance (TMD) also was derived by summing the scores of all six POMS factors (weighting vigour negatively). These inventories assess both psychological states and traits and have been employed in a series of previous investigations cited in the introduction.

\section{Data analysis}

The physiological and psychological parameters were used as independent variables in a multiple regression analysis. For regression analysis, the team was divided into two groups, endurance athletes (distances $\geqslant$ one mile) and power athletes (sprinters and jumpers). A performance score for each subject was computed by expressing his best time, distance, or height as a percent of the then current world record (\% WR) (NCAA Track and Field, 1980), and this percentage was used as the dependent variable in the analysis. The performance score utilised was the subject's best performance in his best event performed during the fall indoor track and field season or the previous spring outdoor track and field season.

Multiple regression analysis requires each subject to have a complete data set. Not all athletes were able to undergo all of the physiological tests. Subject attrition was due to: quitting the team during the testing period, injury, unwillingness to participate in the biopsy procedure. Since missing data presents problems in multiple regression analysis, these values were estimated using another variable with which it was highly correlated (Dixon et al, 1979). Except for fibre type, no variable had more than four missing values. Thus, the number of values estimated was relatively small (see Table I for actual $n$ ). The estimated data were used in calculating all means and correlations.

\section{RESULTS}

Table I lists the variables considered for entry into the multiple regression equations. Mean values for each of the groups are given in Table II. Table III presents the simple correlation coefficients of each variable with performance. Four variables were moderately related to success in distance events and five were related to power performance. No variable was significantly related to both distance and power performance.

\section{Distance running correlates}

The simple correlations (Table III) indicated that body wt, \% ST, LDL-C, and $\bar{X}$ Ham each were related to 
TABLE I

Variables considered in multiple regression model.

\begin{tabular}{|c|c|c|c|c|}
\hline \multirow[b]{2}{*}{ Number } & \multirow[b]{2}{*}{ Variable } & \multicolumn{3}{|c|}{ Actual Number of Subjects } \\
\hline & & $\begin{array}{l}\text { Distance } \\
\text { runners }\end{array}$ & Sprinters & Jumpers \\
\hline 1 & performance - \% of world record (\% WR) & 24 & 10 & 10 \\
\hline 2 & year in college $(y r)$ & 24 & 10 & 10 \\
\hline 3 & maximal oxygen consumption $\left(\mathrm{VO}_{2} \mathrm{max}\right)(\mathrm{ml} / \mathrm{kg} \cdot \mathrm{min})$ & 24 & 9 & 10 \\
\hline 4 & body weight (kg) (wt) & 24 & 10 & 10 \\
\hline 5 & percent body fat ( $\%$ fat) & 24 & 10 & 10 \\
\hline 6 & percent slow twitch fibres (\% ST) & 15 & 7 & 7 \\
\hline 7 & cholesterol (Chol) (mg\%) & 21 & 9 & 7 \\
\hline 8 & high density lipoprotein cholesterol (HDL-C) (mg\%) & 21 & 9 & 7 \\
\hline 9 & low density lipoprotein cholesterol (LDL-C) (mg\%) & 21 & 9 & 7 \\
\hline 10 & mean quadriceps strength $(X$ Quad) $=R Q+L Q / 2(f t-\mid b)$ & 20 & 9 & 10 \\
\hline 11 & mean hamstrings strength $(X \mathrm{Ham})=\mathrm{RH}+\mathrm{LH} / 2(\mathrm{ft}-\mathrm{Ib})$ & 20 & 9 & 10 \\
\hline 12 & right hamstrings/right quadriceps ratio (RH/RQ) & 20 & 9 & 10 \\
\hline 13 & left hamstrings/left quadriceps ratio (LH/LQ) & 20 & 9 & 10 \\
\hline 14 & quadriceps/quadriceps ratio $(\mathrm{Q} / \mathrm{Q})=$ Low $\mathrm{Q} /$ High $\mathrm{Q}$ & 20 & 9 & 10 \\
\hline 15 & hamstrings/hamstrings ratio $(H / H)=$ Low $H / H i g h ~ H$ & 20 & 9 & 10 \\
\hline 16 & extroversion-introversion (Ext-Int) & 24 & 9 & 10 \\
\hline 17 & neuroticism stability (Neu-Stab) & 24 & 9 & 10 \\
\hline 18 & lie & 24 & 9 & 10 \\
\hline 19 & state anxiety (SA) & 23 & 9 & 9 \\
\hline 20 & trait anxiety (TA) & 23 & 9 & 8 \\
\hline 21 & total mood disturbance (TMD) & 24 & 9 & 10 \\
\hline 22 & tension & 24 & 9 & 10 \\
\hline 23 & depression & 24 & 9 & 10 \\
\hline 24 & anger & 24 & 9 & 10 \\
\hline 25 & vigour & 24 & 9 & 10 \\
\hline 26 & fatigue & 24 & 9 & 10 \\
\hline 27 & confusion & 24 & 9 & 10 \\
\hline
\end{tabular}

distance running. Table IV lists variables for each of the three regression equations for the distance runners. These equations were selected because (1) they represented reasonable increases in $R^{2}$ for each variable entered, (2) each variable explained a significant amount of variation, and (3) the predictive power of each model was a significant increase over the previous one.

The standardised regression coefficients from the multiple regression indicated that Chol was the most important predictive variable followed in order by $\mathrm{VO}_{2}$ $\max , \%$ ST, $\bar{x}$ Ham, $\bar{x}$ Quad, RH/RQ, and weight. Three combinations of these variables could explain from $81-89 \%$ of success in distance running.

\section{Power event correlates}

The simple correlations (Table III) indicated that $\mathrm{yr}$ in school, \% fat, $\bar{X}$ Quad, LH/LO, and $Q / Q$ each were related to power event performance. Table IV also contains variables from three multiple regression equations for the power athletes. The same criteria used in selecting equations for the distance runners were used for the sprinters and jumpers.
The multiple regression standardised regression $c 0$ efficients indicated that $\%$ fat was the most important predictive variable. This was followed by $\mathrm{LH} / \mathrm{LQ}$. The remaining variables of $\mathrm{yr}$ in school, body weight, SA, and Ext-Int were of equal importance among themselves in predicting success in power events. Eighty to $86 \%$ of the variance in successful power performance could be explained or accounted for.

\section{DISCUSSION}

Numerous other authors have attempted to characterise track and field participants. However, very few studies have attempted to analyse why some track and field performers are more successful than others. Baseline data on sprinters and jumpers are particularly scarce. In the present study, specific physiological and psychological variables were found to explain a large amount of the variance in successful performance. A limitation of this study was the small number of subjects relative to the number of variables. Thus, the statistical analyses must be interpreted cautiously. 
TABLE II

Average (mean \pm S.D.) physiological and psychological values for each group.

\begin{tabular}{|c|c|c|c|c|}
\hline \multicolumn{2}{|c|}{ \#Variable } & \multicolumn{3}{|c|}{$\begin{array}{l}\text { Distance } \\
(n=24)\end{array}$} \\
\hline 1 & $\%$ WR & 89.5 & \pm 5 & 5.4 \\
\hline 2 & $y r$ & 2.0 & $\pm C$ & 0.9 \\
\hline 3 & $\mathrm{VO}_{2} \max$ & 67.2 & \pm 5 & 5.2 \\
\hline 4 & wt & 67.90 & \pm 6 & 6.81 \\
\hline 5 & $\%$ fat & 8.0 & \pm 2 & 2.1 \\
\hline 6 & $\%$ ST & 79 & \pm 1 & \\
\hline 7 & Chol & 155 & \pm 15 & \\
\hline 8 & HDL-C & 47 & $\pm \varepsilon$ & 8 \\
\hline 9 & LDL-C & 91 & \pm 16 & \\
\hline 10 & $\underline{\bar{x}}$ Quad & 125 & $\pm 1 \mathrm{~s}$ & \\
\hline 11 & $\overline{\mathbf{x}}$ Ham & 82 & \pm 11 & \\
\hline 12 & $\mathrm{RH} / \mathrm{RO}$ & 0.65 & \pm & 0.08 \\
\hline 13 & LH/LQ & 0.67 & \pm & 0.08 \\
\hline 14 & $\mathbf{Q} / \mathbf{Q}$ & 0.92 & \pm & 0.05 \\
\hline 15 & $\mathrm{H} / \mathrm{H}$ & 0.93 & \pm & 0.04 \\
\hline 16 & Ext-Int & 12.0 & \pm 4 & 4.1 \\
\hline 17 & Neu-Stab & 8.4 & & 4.5 \\
\hline 18 & Lie & 3.2 & & 2.8 \\
\hline 19 & SA & 35.4 & & 8.4 \\
\hline 20 & TA & 34.1 & & 8.5 \\
\hline 21 & TMD & 24.4 & $\pm 2 s$ & 9.3 \\
\hline 22 & tension & 10.0 & & 5.9 \\
\hline 23 & depression & 8.3 & & 7.7 \\
\hline 24 & anger & 8.6 & \pm & 7.8 \\
\hline 25 & vigour & 20.3 & \pm & 5.1 \\
\hline 26 & fatigue & 8.8 & \pm & 6.1 \\
\hline 27 & confusion & 7.8 & \pm & 5.3 \\
\hline
\end{tabular}

\begin{tabular}{|c|c|}
\hline \multicolumn{2}{|c|}{$\begin{array}{c}\text { Sprinters } \\
(n=10)\end{array}$} \\
\hline 93.4 & $\pm \quad 3.5$ \\
\hline 2.2 & \pm 1.2 \\
\hline 51.5 & \pm 4.9 \\
\hline 75.08 & \pm 7.60 \\
\hline 2.3 & \pm 2.8 \\
\hline 60 & \pm 14 \\
\hline 60 & \pm 34 \\
\hline 51 & \pm 11 \\
\hline 94 & \pm 27 \\
\hline 68 & \pm 9 \\
\hline 97 & \pm 12 \\
\hline 0.60 & .09 \\
\hline 0.55 & .05 \\
\hline 0.92 & \pm 0.06 \\
\hline 0.93 & \pm 0.06 \\
\hline 13.1 & \pm 2.3 \\
\hline 10.0 & \pm 4.6 \\
\hline 3.0 & \pm 1.5 \\
\hline 38.9 & \pm 9.4 \\
\hline 34.8 & \pm 5.6 \\
\hline 18.5 & \pm 20.0 \\
\hline 12.4 & \pm 7.1 \\
\hline 8.1 & $\pm \quad 5.7$ \\
\hline 5.4 & \pm 4.7 \\
\hline 20.4 & \pm 4.6 \\
\hline 5.7 & \pm 4.9 \\
\hline 7.3 & \pm 3.6 \\
\hline
\end{tabular}

\begin{tabular}{|c|c|c|}
\hline \multicolumn{3}{|c|}{$\begin{array}{l}\text { Jumpers } \\
(n=10)\end{array}$} \\
\hline 32.6 & & 6.6 \\
\hline 1.7 & \pm 1 & 1.1 \\
\hline 55.5 & \pm 5 & 5.6 \\
\hline 73.16 & \pm & 6.45 \\
\hline 4.6 & \pm & 2.0 \\
\hline 60 & \pm 1 & \\
\hline 66 & \pm 2 & \\
\hline 48 & \pm 1 & \\
\hline 02 & \pm 16 & \\
\hline 49 & \pm 23 & \\
\hline 98 & \pm 1 & \\
\hline 0.65 & & .09 \\
\hline 0.68 & & .12 \\
\hline 0.86 & & 0.08 \\
\hline 0.92 & \pm & 0.06 \\
\hline 14.2 & & 4.4 \\
\hline 9.6 & \pm & 2.9 \\
\hline 1.8 & & 1.5 \\
\hline 31.8 & \pm & 5.8 \\
\hline 37.4 & & 8.1 \\
\hline 24.9 & \pm 2 & 1.2 \\
\hline 10.4 & \pm & 5.4 \\
\hline 7.9 & \pm & 5.2 \\
\hline 6.9 & \pm & 7.3 \\
\hline 19.2 & \pm & 4.0 \\
\hline 10.6 & \pm & 6.4 \\
\hline 8.3 & \pm & 3.4 \\
\hline
\end{tabular}

Power

Sprinters \& Jumpers

( $n=20)$

$88.0 \pm 7.6$

$2.0 \pm 1.1$

$53.5 \pm 5.5$

$74.13 \pm 6.93$

$3.5 \pm 2.6$

$60 \pm 13$

$163 \pm 29$

$50 \pm 11$

$98 \pm 22$

$153 \pm 20$

$98 \pm 14$

$0.63 \pm 0.09$

$0.62 \pm 0.11$

$0.89 \pm 0.08$

$0.93 \pm 0.06$

$13.6 \pm 3.5$

$9.8 \pm 3.8$

$2.4 \pm 1.6$

$35.4 \pm 8.4$

$36.1 \pm 6.9$

$21.7 \pm 20.3$

$11.4 \pm 6.3$

$8.0 \pm 5.3$

$6.2 \pm 6.0$

$19.8 \pm 4.2$

$8.2 \pm 6.1$

$7.8 \pm 3.4$

\section{Distance Runners}

Multiple regression. Plasma Chol, maximal oxygen consumption, fibre type and leg muscle strength and balance appeared most often in the regression analysis as correlates of success in distance running (Table IV). The variables considered together could explain between 81 and $89 \%$ of the variance in successful performance. Gutin and others (1975) using $\mathrm{VO}_{2}$ max and submaximal heart rate reported an $R^{2}$ of 0.64 in predicting one mile performance and 0.86 in predicting two mile performance of collegiate track athletes. Using submaximal heart rate and weight, the $R^{2}$ 's were 0.60 and 0.89 for one and two mile performance, respectively.

Farrell and others (1979) examined multiple correlates of distance running success in 18 experienced distance runners. Multiple regression analysis showed that running speed corresponding to the onset of plasma lactate accumulation (anaerobic threshold) was closely related to performance $\left(R^{2}=0.94\right)$ and the addition of $\% \mathrm{ST}$ and $\mathrm{VO}_{2}$ max did not significantly raise $\mathrm{R}^{2}$.
Single correlations. Simple correlations indicated that specific physiological variables were only moderately related to performance (Table III). Wt, \% ST, LDL-C, and $\bar{X}$ Ham were significantly correlated to distance running performance. Other authors have noted lower LDL-C in elite compared with good distance runners (Martin et al, 1977), and total Chol values may be related to mileage accomplished (Hartung et al, 1980). HDL-C was not a significant predictor in the present study. While runners have higher HDL-C values than non runners, values are similar in elite and good distance runners (Martin et al, 1977). The moderate association between LDL-C and performance may be related to dietary or training factors. None of the plasma lipids were related to power performance. Others have reported similar lipid profiles in sprinters and distance runners although runners may have higher HDL-C values (Nikkila et al, 1978: Thomas and Etheridge, 1981).

Successful distance runners appear to have a high percentage of slow-twitch fibres (Costill et al, 1976b). The present results of both the multiple regression and 
TABLE III

Single correlations of each variable with performance (\% of World Record).

\begin{tabular}{|c|c|c|c|}
\hline Number & Variable & $\begin{array}{l}\text { Distance Runners } \\
\qquad n=24\end{array}$ & $\begin{array}{c}\text { Power Athletes } \\
n=20\end{array}$ \\
\hline 2 & $\mathrm{yr}$ & 0.26 & $0.48^{*}$ \\
\hline 3 & $\mathrm{VO}_{2} \max$ & 0.23 & -0.26 \\
\hline 4 & wt & $0.46^{*}$ & 0.37 \\
\hline 5 & $\%$ fat & -0.15 & $-0.46^{*}$ \\
\hline 6 & $\% \mathrm{ST}$ & $0.50^{*}$ & 0.11 \\
\hline 7 & Chol & -0.37 & -0.22 \\
\hline 8 & HDL-C & -0.02 & 0.09 \\
\hline 9 & LDL-C & $-0.40^{*}$ & -0.25 \\
\hline 10 & $\bar{x}$ Quad & 0.27 & $0.45^{*}$ \\
\hline 11 & $\bar{x}$ Ham & $0.40^{*}$ & 0.03 \\
\hline 12 & $\mathrm{RH} / \mathrm{RQ}$ & 0.17 & -0.19 \\
\hline 13 & LH/LQ & 0.02 & $-0.59^{*}$ \\
\hline 14 & $\mathrm{Q} / \mathrm{Q}$ & 0.06 & $0.51^{*}$ \\
\hline 15 & $\mathrm{H} / \mathrm{H}$ & 0.01 & 0.21 \\
\hline 16 & Ext-Int & -0.14 & -0.24 \\
\hline 17 & Neu-Stab & -0.24 & 0.15 \\
\hline 18 & lie & 0.19 & 0.20 \\
\hline 19 & SA & 0.10 & 0.30 \\
\hline 20 & TA & 0.14 & -0.21 \\
\hline 21 & TMD & 0.01 & -0.16 \\
\hline 22 & tension & 0.01 & -0.07 \\
\hline 23 & depression & -0.20 & 0.09 \\
\hline 24 & anger & 0.06 & 0.02 \\
\hline 25 & vigour & 0.08 & 0.31 \\
\hline 26 & fatigue & 0.22 & -0.33 \\
\hline 27 & confusion & -0.12 & -0.05 \\
\hline
\end{tabular}

${ }^{*} \mathrm{p}<0.05$, two tailed test simple correlation analysis indicate that \% ST may be an important factor in distance running performance $(\%$ WR). Likewise, Costill et al (1976b) found a significant relationship $(r=-0.62)$ between $\%$ ST and six mile time of good middle and elite distance runners. However, in both studies, successful distance runners exhibited a wide range of \% ST. Foster and others (1978) also noted a moderate relationship between \% ST and one $(r=-0.52)$, two $(r=-0.54)$, and six $(r=$ $-0.55)$ mile times in trained runners.

Hamstrings strength was related to performance in the present study. Other authors have reported strength data on distance runners, but none have correlated strength with performance. In the present study the better runners tended to have greater hamstrings strength. This variable and quadriceps strength both appeared in the multiple regression analysis. Thus leg muscle strength appears an important variable to consider in training programmes for distance runners.

Although body weight was correlated with distance performance, \% fat was not. Previous work has demonstrated the leanness of distance runners (Pollock et al, 1977; Thomas and Etheridge, 1981). Pollock and co-workers (1977), observed little difference in \% fat values between elite and good distance runners. However, the good runners tended to weigh more than the elite runners. Gutin and others (1975) also reported that heavier runners tended to have slower two mile times $(r=0.75)$. In the present study, the more successful distance runners tended to be slightly heavier. The reason for this discrepancy is unclear although height difference may be a possible explanation.

It was surprising that $\mathrm{VO}_{2} \max$ alone was not a

\section{TABLE IV}

\section{Multiple regression models for distance runners and power athletes}

Distance Runners $n=24$ Regression Equation Variables

Equation

1

2

3

Power Athletes $n=20$

Equation

1

2

3
\% fat, LH/LQ, wt, yr
$\%$ fat, LH/LQ, wt, yr, SA
\% fat, LH/LQ, yr, SA, Ext-Int
$\mathbf{R}$

Chol, $\mathrm{VO}_{2}$ max, \% ST, $\bar{x}$ Quad, RH/RO

Chol, $\mathrm{VO}_{2} \max , \% S T, R H / R Q, \bar{x}$ Quad, wt
.899

.808

.843

.945

.892
$R^{2}-$ Variance Explained

Performance as \% of world record was dependent variable.

Variables listed in order of magnitude of the standard regression coefficients.

Complete regression equations available upon request. 
significant correlate to distance running performance, although it did appear in the multiple regression analysis. This variable can reach values over $80 \mathrm{ml} / \mathrm{kg} \cdot \mathrm{min}$ in elite distance runners, and relatively high $\mathrm{VO}_{2}$ max appears to be necessary but not alone sufficient for elite distance performances (1). Davies and Thompson (1979) found $\mathrm{VO}_{2} \max$ and $5 \mathrm{~km}$ and marathon times related, $r=$ -0.85 and -0.82 , respectively, in male marathon runners. Likewise Gutin and others (1975) and Foster and others (1978) found $\mathrm{VO}_{2}$ max to be highly correlated to one, two, and six mile performances in trained distance runners.

In contrast, Conley and Krahenbul (1980) reported no relationship between running performance and $\mathrm{VO}_{2}$ $\max (r=-0.12)$. Costill and others $(1979 b)$ found the best distance performers did not necessarily exhibit the highest $\mathrm{VO}_{2}$ max values. They reported case studies of successful runners with relatively low $\mathrm{VO}_{2}$ max values who were able to run at a very high percentage of their max without producing lactic acid. In addition, other authors (Conley and Krahenbuhl, 1980) have suggested that steady state $\mathrm{VO}_{2}$ (running economy) is more important to distance performance than $\mathrm{VO}_{2} \max$.

\section{Power Athletes}

Multiple regression. The multiple regression analysis indicated that a combination of physiological and psychological variables could explain a large percentage $(>80 \%)$ of the variation in sprinting and jumping performances. Percent fat, leg strength balance, body weight, SA, and Ext-Int were the strongest predictors of power event performance (Table IV). Apparently no previous attempt has been made to correlate multiple variables with sprinting or jumping success.

Single correlations. This analysis revealed that several of the physiological variables were correlated with power performance (Table III). These included yr in school, $\%$ fat, $\bar{X}$ Quad, $L H / L Q$, and $Q / Q$. The importance of leg strength and balance is evident from these results. Other authors (Liemohn, 1978) have examined these variables in relation to the susceptibility to muscle injury, but the present study indicates that leg muscle strength and balances are also important to success. Little data have been collected on the isokinetic strength of sprinters although Campbell (1979) did report similar leg isokinetic strength $\left(60^{\circ} / \mathrm{sec}\right)$ values as those found in the present study. These results indicate that quadriceps strength may be especially important to power events. In addition, the most successful sprinters and jumpers tended to have the highest $\mathrm{LH} / \mathrm{LO}$ and $\mathrm{Q} / \mathrm{O}$ ratios. That is, they exhibited more balanced muscular strength. These variables may need to be measured and manipulated in power athletes for both injury prevention and successful performance.

The most successful sprinters and jumpers tended to have the lowest $\%$ fat. This characteristic may relate to sprint training programmes, weight training, diet, or a genetic component. The sprinters were the most successful track performers in this study, and two were national champions. In addition, all but three of the sprinters and jumpers in the present study were black. The validity of the \% fat formulas for lean black athletes is unknown. We previously have reported the extreme leanness of sprinters and jumpers (Thomas et al, 1981). Pipes (1977) also reported that \% fat values in power athletes were very low. Gutin and other (1975) found heavier collegiate sprinters to be most successful in $100 \mathrm{yd}$ performance, $r=0.87$. This may also indicate the relatively greater muscularity of good sprinters. Regardless, a small relative amount of fat seems important to success in sprinting and jumping events.

Year in school or grade level was also related to power performance. That is, the upper classmen tended to perform better. This may be a result of maturity, technique, training, or selective attrition.

Other authors have reported low \% ST values in sprinters and jumpers (Bergh et al, 1978). The range of $\%$ ST is often large in these athletes although a certain percentage of fast twitch fibres $(>50 \%$ ?) may be necessary for elite sprinting and jumping performance. Singularly, \% ST was not correlated significantly to success in the present study, nor did it make a significant contribution in the multiple regression analysis.

Generally, the distance runners and power athletes exhibited similar psychological profiles, with both groups comparing favourably with published college norms (Eysenck et al, 1968; McNair et al, 1971; Spielberger et al, 1970). In other words, they displayed superior mental health on the assessed psychological variables, which further supports the belief that positive mental health is a prerequisite for high-level athletic performance (Morgan, 1979). In addition, these athletes are very similar psychologically to outstanding athletes from other sports such as wrestling, cycling, marathon running, and rowing.

In an attempt to identify psychological characteristics related to successful athletic performance, Morgan (1968) found extraversion to be significantly correlated with performance $(r=0.50)$ in world class wrestlers; however, neuroticism was not. Morgan and Costill (1972) reported that neither extraversion, neuroticism, anxiety, or depression was significantly correlated to marathon performance. On the other hand, Nagle et al (1975) and Williams (1977) found both physiological and psychological variables to be significant in predicting successful wrestling and rowing performances, respectively. Furthermore, Morgan and Johnson (1978) have demonstrated an accuracy of $70 \%$ in predicting the selection of national crew teams on the basis of psycho- 
logical data. It is possible that psychological variables were not more closely related to distance performance in this study because this group was not world class. However, SA and Ext-Int were important in predicting performance for power athletes, and this group included national class athletes.

\section{CONCLUSIONS}

The results of this study indicate that: 1. Physiological and psychological variables can be used to explain successful performance in track and field. 2. Physiological variables appear to be more closely related to performance than psychological variables. 3. Plasma
Chol, $\mathrm{VO}_{2} \max , \% \mathrm{ST}, \overline{\mathrm{X}}$ Ham and $\overline{\mathrm{X}}$ Quad strength are the most important correlates of successful distance running. 4. Power performance is most related to \% fat, leg strength and balances, $\mathrm{yr}$ in school, and psychological factors. 5. Physiological correlates to successful performance are different in distance runners and power athletes.

\section{ACKNOWLEDGEMENTS}

The authors thank coaches Robert Timmons and Richard Bowman for their assistance and co-operation and Mike Farmer, RPT, and Scott Smith, RPT, for their assistance in the strength testing.

\section{REFERENCES}

Bergh, U., Thorstensson, A., Sjodin, B. et al, 1978 "Maximal oxygen uptake and muscle fiber types in trained and untrained humans". Med.Sci.Sports 10: 151-154.

Campbell, D. E., 1979 "Generation of horsepower at low and high velocity by sprinters and distance runners". Res. $Q$. 50: 1-8.

Conley, D. L. and Krahenbuhl, G. S., 1980 "Running economy and distance running performance of highly trained athletes". Med.Sci.Sports Exercise 12: 357-360.

Costill, D. L., Daniels, J., Evans, W. et al, 1976a "Skeletal muscle enzymes and fiber composition in male and female track athletes". J.Appl.Physiol. 40: 149-154.

Costill, D. L., Fink, W. J. and Pollock, M. L., 1976b "Muscle fiber composition and enzyme activities of elite distance runners". Med.Sci.Sports 8: 96-100.

Davies, C. T. M. and Thompson, M. W., 1979 "Aerobic performance of female marathon and male ultramarathon athletes". Eur.J.Appl.Physiol. 41: 233-245.

Dixon, W. J. and Brown, M. B. (eds.), 1979 BMDP-79, “Biomedical computer programs P-Series”. Berkeley, California: University of California Press.

Dubowitz, V. and Brooke, M. H., 1973. Muscle Biopsy: A Modern Approach. Philadelphia, W. B. Saunders, pp. 5-33.

Eysenck, H. J. and Eysenck, S. B. G., 1968. Manual for the Eysenck Personality Inventory. Educational and Industrial Testing Service: San Diego.

Farrell, P. A., Wilmore, J. H., Coyle, E. F. et al, 1979 "Plasma lactate accumulation and distance running performance". Med.Sci.Sports 11: 338-344.

Foster, C., Costill, D. L., Daniels, J. T. et al, 1978 "Skeletal muscle enzyme activity, fibre composition and $\mathrm{VO}_{2}$ max in relation to distance running performance". Eur.J.Appl.Physiol. 39: 73-80.

Gutin, B., Torrey, K., Welles, R. et al, 1975 "Physiological parameters related to running performance in college trackmen". J.Human Ergol. 4: 27-34.

Hagberg, J. M., Mullin, J. P., Bahrke, M. et al, 1979 "Physiological profiles and selected psychological characteristics of national class American cyclists". J.Sports Med.Phys.Fit. 19: 341-346.

Hartung, G. H. and Squires, W. G., 1980 "Exercise and HDL cholesterol in middle-aged men". Phys.Sportsmed. 8: 74-79. 
Liehmohn, W. E., 1978 “Factors related to hamstring strains”. J.Sports Med.Phys.Fit. 18: 71-75.

Martin, R. P., Haskell, W. L. and Wood, P. D., 1977 "Blood chemistry and lipid profiles of elite distance runners". Ann. NY Acad.Sci. 301: 346-360.

McNair, D. M., Lorr, M. and Droppleman, L. F., 1971 "Profile of mood state manual". Educational and Industrial Testing Service: San Diego.

Morgan, W. P., 1973 "Efficacy of psychobiologic inquiry in the exercise and sport sciences". Quest 20.

Morgan, W. P., 1968 "Personality characteristics of wrestlers participating in the world championships". Int.J.Sport Psychol. 8: 212-216.

Morgan, W. P., 1979 "Prediction of performance in athletics". In Coach, Athlete and the Sport Psychologist, P. Klavora and S. V. Daniel, eds., Champaign, Illinois, Human Kinetics.

Morgan, W. P. and Costill, D. L., 1972 "Psychological characteristics of the marathon runner". J.Sports Med.Phys. Fit. 10: $42-46$.

Morgan, W. P. and Johnson, R. W., 1973 "Personality characteristics of successful and unsuccessful oarsmen". Int.J. Sport Psychol. 9: 119-133.

Morgan, W. P. and Pollock, M. L., 1977 "Psychologic characterization of the elite distance runner". Ann.NY Acad. Sci. 301: 382-4-3.

Nagle, F. J., Morgan, W. P., Hellickson, R. O. et al, 1975 "Spotting success traits in Olympic contenders". Phys.Sportsmed. 3: 31-34.

NCAA Track and Field 1980 Shawnee Mission, KS, National Collegiate Athletic Association, pp. 112-120.

Nikkila, E. A., Taskinen, M. R., Rehunen, S. et al, 1978 "Lipoprotein lipase activity in adipose tissue and skeletal muscle of runners: Relation to serum lipoproteins". Metabolism 27: 1661-1671.

Pipes, T. V., 1977 "Body composition characteristics of male and female track and field athletes". Res.Q. 48: 244-247.

Pollock, M. L., Gettman, L. R., Jackson, A. et al, 1977 "Body composition of elite class distance runners". Ann.NY Acad.Sci. 301: 306-370.

Spielberger, C. D., Gorsuch, R. L. and Loshene, R. E., 1970 "Manual for the State-Trait Anxiety Inventory". Consulting Psychologists, Palo Alto, California.

Thomas, T. R. and Etheridge, G. L., 1981 "The effect of track and field training on cardiovascular fitness". Phys. Sportsmed. 3: 31-34.

Williams, L. R. T., 1977 "The psychobiological model and multiple discriminant function analysis of high calibre oarsmen". Med.Sci.Sports 9: 178-184. 